\title{
Investigation into abrasion resistance of dyed fabrics made of recycled and standard cotton fibres
}

\begin{abstract}
Sustainability of textiles and fashion has been paid attention in recent years. Till now recycling of unwanted clothing into new source of textile materials is one that isn't being explored as intensively as other areas. This research brings to light the valuable source of recycled cotton fibers and to explore ways in which consumers can be made more aware of thesis garments. Fabrics from pairs of jeans, one made of standard cotton fiber and the other made of combination of standard and recycled cotton have been studied. Their abrasion resistance property has been investigated and comparisons were made to identify the quality of the recycled cotton fibers as sustainable alternative to standard cotton fibers.
\end{abstract}

Keywords: recycled jean, property comparison, abrasion resistance
Volume I Issue I - 2017

Tamsin Broman, Danmei Sun

School of Textiles and Design, Heriot-Watt University, UK

Correspondence: Danmei Sun, School of Textiles and Design, Heriot-Watt University, UK, Email D.Sun@hw.ac.uk

Received: August 22, 2016 | Published: January 27, 2017
Abbreviations: BS, british standard; EN, european norm; ISO, international organization for standardization

\section{Introduction}

Recycling is defined as the material properties being reused. The advantage of using recycled materials is that the benefits can be felt rapidly ${ }^{2}$ as material choices can be easily integrated into the manufacturing process. Recycling reduces the amount of landfill space being taken up. With $31 \%$ of textiles in the UK going to landfill and $5 \%$ of all landfill space in America being taken up by textiles, the majority of which could be reused or recycled, ${ }^{3}$ a raised awareness over fashion being made from recycled products could greatly reduce the amount of space and pollution caused.

If more textile items are recycled then the drain on virgin resources can be reduced along with the amount of pollution and energy caused from creating these resources. $87 \%$ of water used in the whole manufacturing process is used just on the raw materials, with $1 \mathrm{~kg}$ of cotton needing between 7,000 and 29,000liters of water ${ }^{4}$ and a cotton $\mathrm{t}$-shirt is estimated to produce $2.1 \mathrm{~kg}$ of greenhouse gas during its production. ${ }^{3}$ There is 2 billion US dollar worth of chemicals used on cotton crops. ${ }^{2}$ This result, not just in pollution of the environment, but also it damaged the health of cotton farmers who have reported health issues due to overexposure to pesticides. Even the most energy concentrated form of synthetic fibre recycling uses up to $80 \%$ less energy than that manufacturing of the virgin resource, and it is the same significant savings for traditional recycling methods. ${ }^{2}$

Denim jeans are normally hard wearing trousers traditionally made from cotton, with more modern versions using other fibres such as polyester and elastane, in twill weave structure. The garment that was once used for work wear ${ }^{5}$ is now a staple garment in the majority of the population's wardrobes. According to a Mintel report taken in 2010 , adults purchase jeans in the UK remains at $51 \%$, with an estimated £1billion being spent on jeans in 2010 alone. The average adult owns 4 pairs of jeans, however $22 \%$ own between 5 and 7 pairs. This is mainly woman under 35years of age; they are also more likely to be the ones who purchase a new pair depending on changing trends. Although $78 \%$ of customers, mainly woman and customers between the ages of 45-54, wear jeans until they are no longer wearable. ${ }^{6}$
With the high amount of jeans being purchase just within the UK it is clear to see that they would have a large impact on the environment, especially due to the cotton that is used for making them, it takes 1.5 pounds of cotton to produce one pair of jeans. ${ }^{7}$ However, and this is just the start of their carbon footprint. The classic Levi 501 jeans takes $32.3 \mathrm{~kg}$ of $\mathrm{CO} 2,3480.5$ litres of water and $400.1 \mathrm{~mJ}$ of energy to produce, this is the equivalent of driving 78 miles, taking 7 minutes showers 53 times and powering a computer for 556 hours. ${ }^{8}$ The water impact is the most noted issue with denim jean production; however they actually manufacturing process takes very little, only $6 \%$, whereas the water used in the field equals $49 \%$ of water used in jeans manufacturing and the other $45 \%$ is with consumers. ${ }^{9}$ Considering that out of the 2 billion pairs produced annually ${ }^{10} 97 \%$ ends up in the incinerator or landfill every year, ${ }^{4}$ all of these resources being used is careless and almost needless.

There is limited information available on the quality of recycled fibres, especially natural fibres such as cotton. However, it is known that the recycling process for cotton results in a shorter fibres being produced. There are two different forms of waste used in recycled pre-consumer and post-consumer. Within pre-consumer waste are two sub categories - re-workable or non-reworkable. Reworkable waste is the waste that can be put straight back into spinning from areas such as carding, combing and drawing for example. Non-reworkable must be treated before it can be respun and comes from areas such as fabric processing and post-consumer waste. ${ }^{11}$

Virgin fibres are combined with the waste fibres to make the spinning processes can be easier and to improve the quality of the yarn; however the waste material must be of an adequate standard to produce yarn with as little virgin fibres as possible. ${ }^{11}$ Textile waste can be blended up to $20 \%$ with virgin cotton fibres with no difference in the yarn quality. ${ }^{12}$

A study was conducted comparing socks containing reclaimed cotton fibres and virgin polyester fibres against socks containing $100 \%$ virgin cotton fibres which tested density parameters, mass and thickness as well as air permeability, bursting strength and abrasion resistance. The study uses socks that contain elastane and those that don't as well as 3 different stitch lengths. It was found that the air permeability of the reclaimed fibres socks was always lower 
than those made from virgin fibres. Whereas the pilling tendencies of the reclaimed fibre socks had a tendency to be higher than those containing virgin fibres although the pilling grade overlaps from the reclaimed fibre socks to virgin fibres socks. For example, with socks containing elastane with a short stitch length the reclaimed fibre socks had a pilling grade of 2 whilst the virgin fibre had a grade of 2-3. This is down to the reclaimed polyester being used, which increased the abrasion resistance. Overall, the bursting strength of the virgin fibre socks is higher except in the case of the reclaimed socks containing elastane with medium and long stitch lengths, which have a higher bursting strength. The author of the study states that the adequate burst strengths allow reclaimed yarns to be used for sock production. ${ }^{11}$

It is said that consumers are becoming more aware of where their products are being produced and how this has an effect on the environment and people. However, there is a significant gap between consumer's attitude and their actions. Half of Europeans say they would pay more for a product that was sustainable and 55\% of respondents on a green survey say they are more attracted to a company if they are environmentally friendly ${ }^{13}$ although the market share for sustainable products is a meager $1 \%$.

This paper will reports the abrasion property of denim made of mixture of recycled and standard cotton in comparison to denim made of standard cotton.

\section{Experiment and method}

The denim jeans that are being used in this study contain both virgin cotton and recycled cotton fibres. 3 sets of samples were taken from each pair of jeans, with a diameter of $38+/-0.5 \mathrm{~mm}$ each. The samples were taken from different parts of the jeans (behind the knee, the hem and the front pocket area) from different parts of the jeans. This was to follow the standard which states that they should contain different weft and warp threads, these were then weighed to determine a starting weight to measure the loss that occurs.

The two pairs of jeans were both from the same retailer and contained the same fibre make up (95\% cotton, 5\% elastane) with the cotton in the recycled denim including $20 \%$ recycled cotton and the standard jeans only containing virgin cotton fibres. The fabric specifications are shown in Table 1. This specification table displays the slight difference in the weight of the fabrics, which will in turn slightly affect the results of the data collected and the ability to compare the test results.

Table I Fabric Specifications

\begin{tabular}{|c|c|c|c|c|c|}
\hline \multirow[t]{2}{*}{$\begin{array}{l}\text { Fabric } \\
\text { samples }\end{array}$} & \multicolumn{2}{|c|}{$\begin{array}{l}\text { Yarn count } \\
\text { (Tex) }\end{array}$} & \multicolumn{2}{|c|}{ Fabric set $(/ \mathrm{cm})$} & \multirow[t]{2}{*}{$\begin{array}{l}\text { Fabric weigh } \\
\left(\mathrm{g} / \mathrm{cm}^{2}\right)\end{array}$} \\
\hline & Warp & Weft & Warp & Weft & \\
\hline Standard & 57.39 & 69.17 & 30 & 19 & 0.479 \\
\hline Recycled & 60.88 & 61.82 & 32 & 19 & 0.491 \\
\hline
\end{tabular}

The samples were left in a condition lab for 24hours to ensure they reached the conditions stated in BS EN ISO 139:2005+A1:2011, with a temperature of $20^{\circ} \mathrm{C}$ and a humidity of $65 \%$.

The abrasion test was carried following the British standard BS EN ISO 12947- 3:1998, which is the Martindale method for abrasion resistance in fabric for mass loss. The machine used was the Martindale machine and the test intervals used were as stated in the standard, test series up to 25000 rubs. After each series of rubs the samples were removed and weighed to determine the amount of loss that occurred in that cycle.

To arrange the samples in the Martindale machine the felt and the abradant fabric were the mounted onto the abrading tables, then a weight was placed on top before the clamping ring was placed round the fabric to keep it in place. The denim fabric samples were then placed in a specimen holder nut which sits in a mount, and then there is foam of the same diameter as the sample placed behind it with the specimen holder insert going on after followed by the specimen holder body which is screw on tightly. The specimen holder is placed face down onto the abradant fabric and weights of 9Kpa are placed in the top of the specimen holder body.

\section{Results and discussion}

Pictures were taken after each rub cycle to record any changes to the appearance of the fabric and in case of any damage such as holes or pilling. After each cycle the fabric was weighed and the weight recorded along with a picture being taken to record signs of wear to the fabric. As the fabric was a cotton/elastane composition there wasn't going to be a significant amount of weight loss or damage to the actual sample due to the nature of the denim as it's designed to be a hardwearing fabric. However, there is a relative amount of dye loss, which was transferred to the abradant fabric.

\section{Abrasion resistance of standard denim}

Tables 2-4 show the results of standard Denim sample 1. The starting weight for this sample was $0.470 \mathrm{~g}$, and had an average loss of $0.003 \mathrm{~g}$ after 5000rubs. The picture shows a fair amount of dye transfer from the first sample to the last and once removed from the sample holder it becomes even more apparent. The majority of the dye loss is around the edges of the exposed sample, but there is no fuzzing or damage to the fabric.

The starting weight for the second sample was $0.476 \mathrm{~g}$, and it had an average loss of $0.002 \mathrm{~g}$ per 5000 rubs. There doesn't appear to be as much wear to this sample and unfortunately this was cut on a crease, it was a sample taken from behind the knee area. However, it does show the difference in the first picture where the crease line is of a similar shade to the rest of the sample and the final image where the crease line is much more pronounced than the rest of the sample, especially along the edges of the crease. It also appears quite patchy the fading of the dye but again there is no fuzzing or damage to the fabric. The final standard denim sample had a starting weight of $0.490 \mathrm{~g}$ with an average loss of $0.003 \mathrm{~g}$ per 5000rubs. Like the second sample this doesn't appear to be as much wear to it. However, it does appear patchy where the dye has faded and this also shows there is no fuzzing or damage to the fabric.

\section{Abrasion resistance of recycled denim}

Tables 5-7 show the abrasion test results of recycled denim samples. The starting weight for first sample was $0.475 \mathrm{~g}$, and had an average loss of $0.002 \mathrm{~g}$ per 5000rubs. The pictures show a fair amount of dye and surface fibres have rubbed away from around the edge of the sample, which is clearer once removed from the sample holder. This clearly shows that areas of high abrasion would have a significant amount of dye and fibre loss after a certain amount of time. In this case it was 25,000 rubs. 
Table 2 Abrasion resistance result of standard Denim Sample I

刑

刑 5000 Cycles 10,000 Cycles 15,000 Cycles 25,000 Cycles
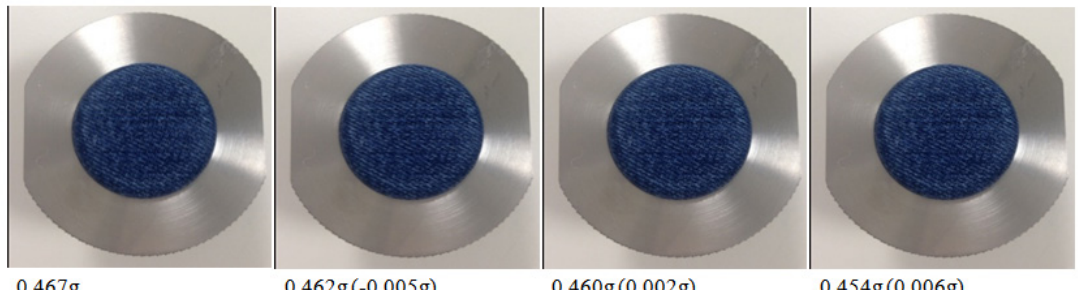

Table 3 Abrasion resistance result of standard Denim Sample 2

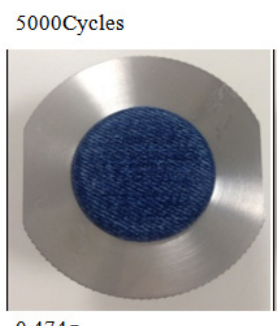

10,000 Cycles

15,000 Cycles

25,000 Cycles

$0.474 \mathrm{~g}$

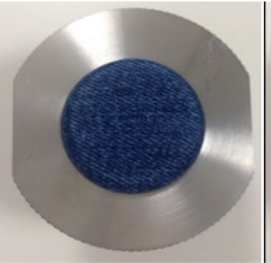

$0.472 \mathrm{~g}(-0.002)$

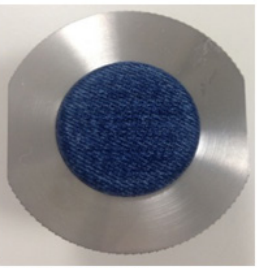

$0.471 \mathrm{~g}(-0.001 \mathrm{~g})$

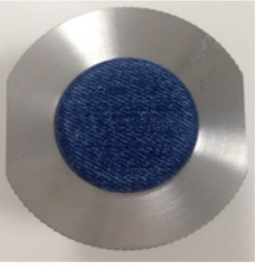

$0.467 \mathrm{~g}(-0.004)$

Table 4 Abrasion resistance result of standard Denim Sample 3

5000 Cycles

10,000 Cycles

15,000 Cycles

25,000 Cycles

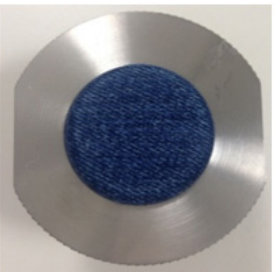

$0.488 \mathrm{~g}$

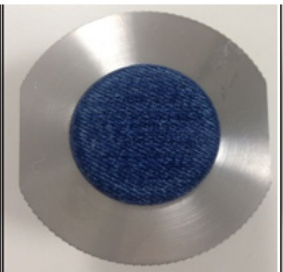

$0.486 \mathrm{~g}(-0.002 \mathrm{~g})$

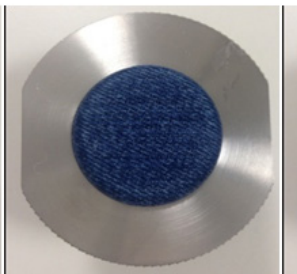

$0.484 \mathrm{~g}(-0.002 \mathrm{~g})$

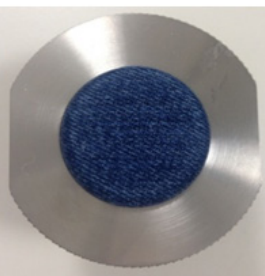

$0.477 \mathrm{~g}(-0.007 \mathrm{~g})$

Table 5 Abrasion resistance results of recycled Denim Sample I

5000 Cycles

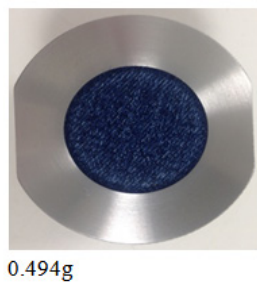

10,000 Cycles

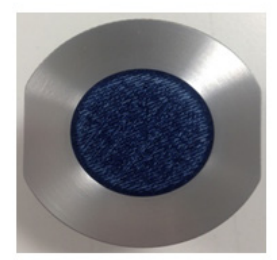

$0.492 \mathrm{~g}(-0.002 \mathrm{~g})$
15,000 Cycles

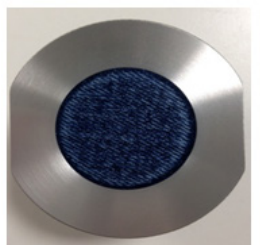

$0.489 \mathrm{~g}(-0.003 \mathrm{~g})$
25,000 Cycles

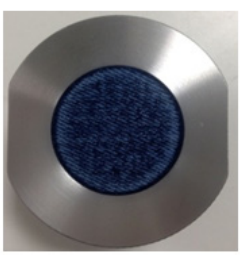

$0.485 \mathrm{~g}(-0.004 \mathrm{~g})$

Table 6 Abrasion resistance results of recycled Denim Sample 2

5000 Cycles

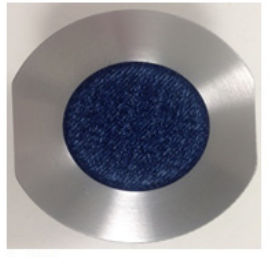

$0.494 \mathrm{~g}$
10,000 Cycles

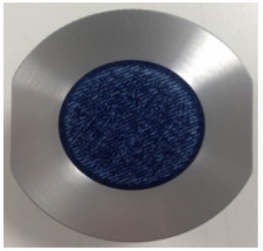

$0.492 \mathrm{~g}(-0.002 \mathrm{~g})$
15,000 Cycles

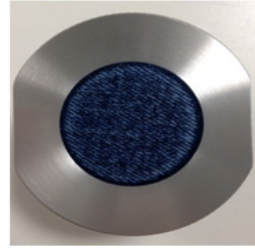

$0.489 \mathrm{~g}(-0.003 \mathrm{~g})$
25,000 Cycles

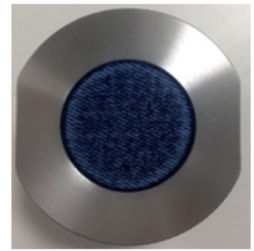

$0.485 \mathrm{~g}(-0.004 \mathrm{~g})$ 
Table 7 Abrasion resistance results of recycled Denim Sample 3
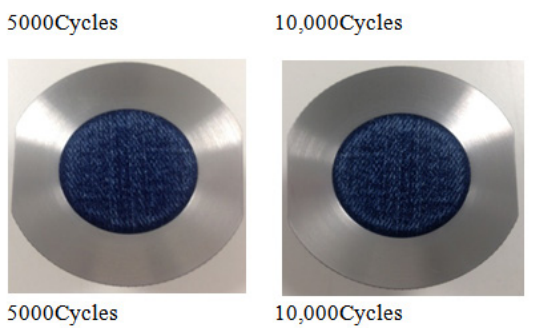

10,000 Cycles

The starting weight for the second sample was $0.496 \mathrm{~g}$, and it had an average loss of $0.002 \mathrm{~g}$ per 5000rubs, the same as sample one even though the loss increased gradually with this sample unlike the last one. There appears to be a more obvious ring of wear around the final sample than in the first recycled sample, although it isn't as wide as the other as in the first sample. The transfer to the abradant fabric is a lot more than in the first sample taken from the recycled denim. The way in which the dye has faded is patchy but like all the samples taken there is no fuzzing or damage to the fabric.

The final recycled denim sample had a starting weight of $0.503 \mathrm{~g}$ with an average loss of $0.002 \mathrm{~g}$ per 5000rubs, which again is like the other recycled denim samples but not with the same consistency as the first sample. This has a slight crease in the fabric much like the standard denim sample 2, which becomes more prominent as the number of rubs increases. Whilst it appears patchy where the dye has faded it isn't as patchy as the previous two samples and the sample also shows no signs of fuzzing or damage to the fabric.

\section{Abrasion resistance comparison}

All together the recycled denim samples had an average loss of $0.002 \mathrm{~g}$ per 5000rubs compared with the average of $0.003 \mathrm{~g}$ loss from the standard denim. Since this isn't a significant difference it is assumed that the recycled fibres are on the same level as the virgin fibres that were used since they haven't made a considerable difference to how the denim would wear, therefore the worries of durability is unfounded and recycled fibres can be a viable choice for garment in respect to their abrasion resistance.

Appearance wise it is difficult to determine which samples had a larger dye and fibre loss, as the recycled denim jeans were little bit darker to begin with than the standard denim. This can be seen in Table 8 . The fading appears more consistent on the standard denim, whereas the recycled denim looks patchy especially in the final two samples. However, the recycled denim looks as though it has faded less than the standard denim. This suggests that the dye has held stronger to the recycled denim but there is a factor that is preventing it from fading as nicely as the standard denim and it can't be assumed that it is the recycled fibres that are the factor at fault. Whilst this is a small issue, it is one that would need to be explored in further tests. It is also not a serious loss of dye and fibres that it would potentially put off consumers; this again means recycled fibres can be seen as a viable choice for sustainable garments.

The technology for recycling fibres hasn't had much research or development done on it; the lack of literature gives an indication to this. Industry needs to work on ways in which natural fibres can be recycled that doesn't damage them as much and ensuring the fibres are kept longer to increase the durability which in turn would mean more recycled fibres could be used in garments. This could potentially

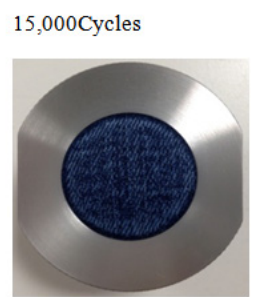

15,000 Cycles
25,000 Cycles

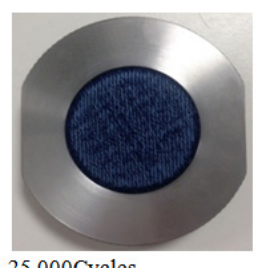

25,000 Cycles

increase the amount of garments being produced containing recycled fibres.

Table 8 Final sample comparison of standard and recycled Denim
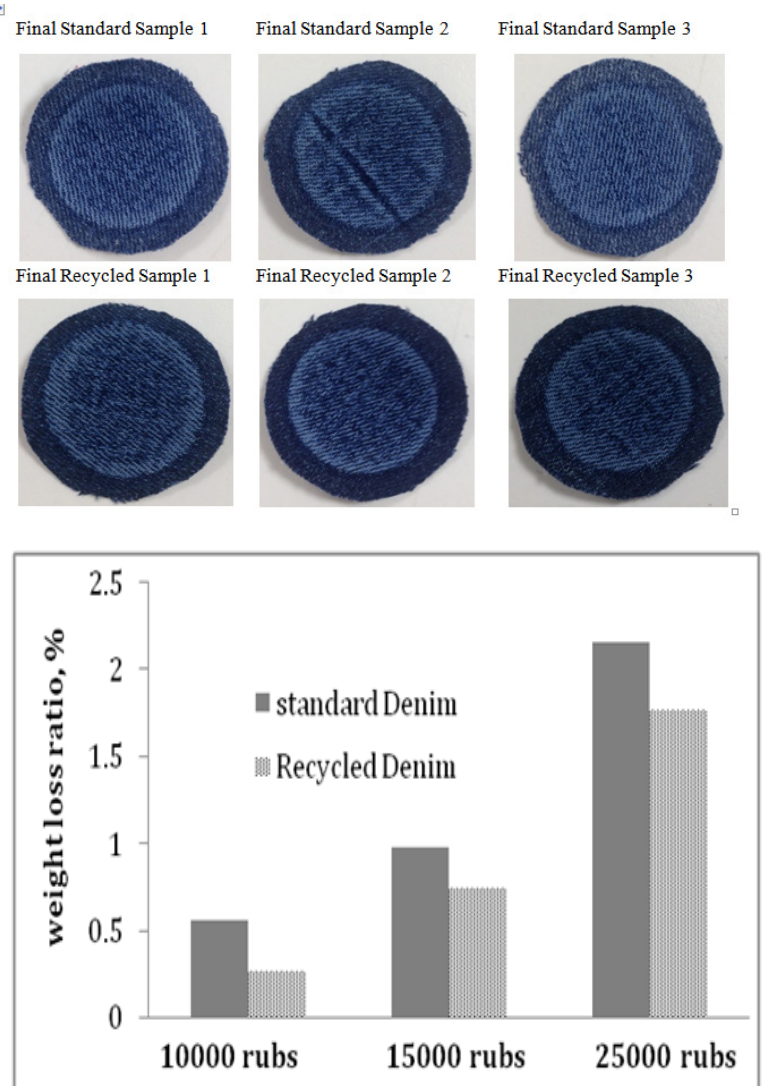

Figure I Weight loss comparison between standard and recycled Denim.

\section{Conclusions, limitations and recommenda- tions}

As it stands the fashion industry produces more waste than is sustainable, and there are more clothing going to landfill than is necessary. An easy solution to this is through recycling old garments into new. The consumer concern over durability was proven to an extent to be unfounded through lab tests. The abrasion test showed that the recycled denim, whilst slightly weaker, compared well with the standard denim. However, it would be beneficial to perform the test on fabric of the same quality and to perform further tests. It has been suggested that to further increase consumers' confidence in recycled denim the technology for recycling the old garments needs 
to be greatly improved for the likes of natural fibres so that more can be used as well as increasing the strength of the fibres.

The different weight of the two fabrics caused for the abrasion test was the fact; the recycled fabric was heavier than the other. Also when comparing colour loss it is difficult to see which loses colour and surface fibres quicker because darker denim is more likely to lose dye due to the nature of the dye. The tests chosen however still answered the concerns about durability whilst fitting to the British Standards used.

Further tests should be run to get a proper indication of how the recycled garments stand against the standard garments by knowing the percentage of recycled fibres contained in recycled denim. Other objective and subjective evaluation need to be carried out such as tensile strength, wear trial, etc.

\section{Acknowledgments}

None.

\section{Conflict of interest}

Author declares there is no conflict of interest in publishing the article.

\section{References}

1. Karin ME, Nicklas S. Reuse and recycling of clothing and textiles-a network approach. Journal of Macro marketing. 2014;34(3):383-399.
2. Kate Fletcher, Lynda Grose, Paul Hawken. Fashion \& sustainability: design for change. 1st ed. Laurence King, London, England; 2012.

3. H\&M Conscious Actions: Sustainability Report 2013. Sweden; 2013.

4. Deloitte. Fashion Sustainability 2013: Redesigning the Fashion Business. Deloitte Touche Tohmatsu Limited, UK; 2013.

5. Jeans West. 2015.

6. Sender T. Jeans - Consumer Attitudes to Buying and Wearing UK - November 2010. Mintel Academic, UK; 2010.

7. Glausiusz J. How Green Are Your Jeans. On Earth. 2008.

8. Levi Strauss. A Product Lifecycle Approach to Sustainability. San Francisco, USA; 2009. p. 28.

9. Berfield S. Levi's Has a New Colour for Blue Jeans: Green. Blooberg Business Weekly. 2012. p. 26-28.

10. Burridge E. Clairant Offers a Greener Blue Denim Process. ICIS Chemical Business. 2012.

11. Guna AD, Hatice NA, Macit AS, et al. Dimensional and physical properties of socks made from reclaimed fibre. The Journal of The Textile Institute. 2014;105(10):1108-1117.

12. Halimi Mohamed Taher, Azzouz B, Ben Hassen MD, et al. Influence of Spinning Parameters and Recovered Fibers from Cotton Waste on the Uniformity and Hairiness of Rotor Spun Yarn. Journal of Engineered Fibers and Fabrics. 2009;4(3):36-44.

13. Toohey C. Making Green Worthwhile. Mintel, UK; 2013. 